\section{TOXIC EFFECTS OF THE WORK ENVIROMENT - A RETROSPECTIVE 5 YEARS STUDY IN THREE TEXTILE FACTORIES}

${ }^{1}$ RM Stamatin*, ${ }^{2} \mathrm{C}$ Petrea. ${ }^{1} \mathrm{~A}$. Popescu' Emergency Military Hospital, Focşani, Romania; ${ }^{2}$ National Sanitary Veterinary Authority - Vrancea County, Focsani, Romania

10.1136/oemed-2018-ICOHabstracts. 1280

Introduction Several types of natural fibres used in textile/ clothing industry causes respiratory diseases, such as: asthma, allergic rhinitis, allergic alveolitis, chronic obstructive pulmonary disease (COPD), whose number has increased constantly over the last few years. The respiratory adverse effects of professional exposure to natural fibres dust (as cotton, wool, flax, cashmere) in the textile industry was first described several centuries ago as a syndrome later called byssinosis. Then, World Health Organisation included other criterias to differentiate and to diagnose long-time respiratory disease.

Methods A number of 1180 employees from three garments factories were monitored (on the occasion of the annual medical examination), between May-September, synchronous with the professional pollutant determinations (cotton, linen, wool, carried out by the Public Health Authority of the county). Spirometry has also been performed on all employees.

Results Although the dust determinations were within the limits imposed by the local legislation in force, we found that values close to the upper limit of normal are associated with a higher concentration of respiratory pathological phenomena and changes in spirographic parameters. Increased humidity, high temperature, and low or zero airflow rates at work create more significant changes in respiratory indices, especially on the first working day of the week (Monday-morning syndrome).

Discussion The textile industry is an important sector of concentration of professional respiratory pathology. The microclimate of the workplace, the concentration and type of textile dust, as well as the personal illness history (recurrent respiratory infections, extraprofessional allergens, psychosocial factors - stress, and neuro-endocrine factors, as well as physical effort) contribute to the initiation and maintenance of physiopathological mechanisms. Cessation of exposure and correction of professional factors lead, in most cases, to remission of symptoms and improving the quality of life.

\section{THE ASSOCIATION BETWEEN OCCUPATIONAL ASTHMA AND SKIN SENSITISATION TO LOW-MOLECULAR WEIGHT AGENTS: A SYSTEMATIC REVIEW}

${ }^{1}$ Hung-Chang Tsui ${ }^{*},{ }^{2}$ Laurens De Sadeleer, ${ }^{1}$ Jeroen Vanoirbeek, ${ }^{1}$ Peter Hoet, ${ }^{1}$ Benoit Nemery. ${ }^{1}$ Centre for Environment and Health, Department of Public Health and Primary Care, KU Leuven, Leuven, Belgium; ' Laboratory of Respiratory Diseases, KU Leuven, Leuven, Belgium

\subsection{6/oemed-2018-ICOHabstracts. 1281}

Introduction Occupational asthma is one of the most frequent forms of work-related lung disease in industrialised countries. Mounting evidence suggests that low-molecular-weight (LMW) agents, such as isocyanates and anhydrides, are linked to the development of occupational asthma through skin exposure and sensitisation. This review aimed to provide an overview of all reported LMW agents exhibiting evidence of inducing respiratory sensitisation via skin exposure.

Methods We conducted a database search with MEDLINE/ PubMed and Embase. We included animal studies that investigated the potential of LMW agents to elicit respiratory responses after airway challenge after prior skin sensitisation; epidemiological studies that evaluated the association between skin exposure to LMW agents and occupational asthma; and case reports of occupational asthma and concurrent allergic dermatitis caused by LMW agents. One person conducted the search and first screening. Two reviewers independently performed the final selection using full-text reports.

Results Of 6949 identified articles, 306 studies were included: 83 animal studies, 45 epidemiological studies, 99 case reports, 37 reviews and 38 other types of articles. The 83 animal studies concerned 36 different LMW agents, with trimellitic anhydride (TMA), toluene diisocyanate (TDI), and diphenylmethane diisocyanate (MDI) being studied most frequently, mostly in BALB/c mice, Brown Norway rats, and Hartley guinea pigs. The appraisal of the human studies is ongoing.

Discussion This systematic review summarises the recent research progress on the association between asthma and skin sensitisation to LMW agents. An improved evidence-based understanding in this field should facilitate the control of exposure to chemical sensitizers in the workplace. Moreover, this systematic review will contribute to improve our understanding of the pathogenesis of non-atopic asthma in general.

\section{THE SILICOSIS CASES IN DENTAL TECHNICIANS AT ISTANBUL OCCUPATIONAL DISEASES HOSPITAL}

${ }^{1}$ Bahar Tüzün, ${ }^{1}$ Özkan Kaan Karadağ, ${ }^{1}$ Sezgin Bildik, ${ }^{2}$ Özlem Oruç, ${ }^{3}$ Gül Dabak. ${ }^{1}$ stanbul Occupational Diseases Hospital, Istanbul, Turkey; ${ }^{2}$ Acibadem University, Istanbul, Turkey; ${ }^{3}$ Sureyyapaşa Pulmonary Diseases and Thoracic Surgery Research Hospital, Istanbul, Turkey

\subsection{6/oemed-2018-ICOHabstracts. 1282}

Introduction and aim Silicosis is a kind of parenchymal lung disease caused by inhalation of crystalline silica dust due to occupational and environmental exposure. Crystalline silica is used in many industries including asphalt manufacturing, concrete production, glass manufacturing, mining, quarrying, tunnelling, sandblasting, construction areas, cement production, and also in dental laboratories. Workers and technicians employed in these industries are at the greatest risk of silicosis. In the advanced stages of silicosis, severe functional loss may lead to respiratory insufficiency and death.

This study aims to define the features of silicosis in dental technicians diagnosed at our hospital and attract attention to the occupational hazards in that field.

Method This is a descriptive study with 111 cases diagnosed with silicosis after detailed investigation including clinical situation, occupational history, smoking habits, pulmonary function test results, chest X-ray and high resolution computerised tomography findings of dental technicians between 2007-2016 at Istanbul Occupational Diseases Hospital, Turkey.

Results Mean age is $39.01 \pm 7.87$ years (range 23-61). Total duration of employment is $19.80 \pm 9.07$ years(range 3-48). Mean duration of work per day is $9.82 \pm 2.42$ hours and median is 10 hours. While $37.8 \%(n=42)$ of them had symptoms $62.2 \%$ of cases are asymptomatic $(n=69)$. Of the symptomatic cases, 40.5\% $(n=17)$ had exertional dyspnea, $47.6 \%$ $(n=20)$ had cough. Mean duration of symptoms is 26.63 \pm 26.65 months (1-120 months). 38.7\% ( $=43)$ of cases are active smokers, $34.2 \%(\mathrm{n}=38)$ are nonsmokers and $17.1 \%$ $(n=19)$ of them were exsmokers. The mean amount of cigarettes is $12.35 \pm 7.84$ pack.year (1-33 pack.year) Functionally, FEV1 is $3.29 \pm 0.83$, FEV1 (\%) mean value is $87.80 \pm 19.19$ 